\title{
Analysis of community attributes of the macrobenthos of Frierfjord/Langesundfjord at taxonomic levels higher than species
}

\author{
R. M. Warwick \\ Plymouth Marine Laboratory (West Hoe), Prospect Place, The Hoe, Plymouth PL1 3DH, United Kingdom
}

\begin{abstract}
In connection with the GEEP Workshop multivariate and univariate analyses were made of macrobenthic species abundances and biomass from Frierfjord/Langesundfjord, Norway, with the data aggregated to family and phylum levels. For families, there was no loss of information compared with the species analyses, which augurs well for the worldwide application of the techniques and for the improvement of their cost-effectiveness. For phyla, multivariate analyses varied in the degree to which they reproduced species and family configurations depending on whether abundance or biomass was used and on the strength of data transformation, but generally the agreement was surprisingly good. It is suggested that the results of multivariate analyses based on higher taxa may more closely reflect gradients of contamination or stress than those based on species data, the latter being more affected by natural ('nuisance') environmental variables.
\end{abstract}

\section{INTRODUCTION}

The determination of changes in macrobenthic community structure has featured prominently in programmes to detect the biological effects of marine pollution (Gray et al. 1988). There are, however, some major practical logistic problems associated with this approach. Firstly, for the kinds of multivariate and univariate analyses performed in Gray et al., the sorting, identification and enumeration stages necessary to compile species abundance and biomass arrays require considerable taxonomic expertise and familiarity with the local fauna. This operation is also highly labour intensive. The major hinderance arises in sorting certain difficult groups such as spionid or cirratulid polychaetes, ampeliscid amphipods etc. into species, although most benthic ecologists with only moderate experience can easily and quickly allocate specimens to these families. Often the analysis of these difficult groups can take far longer than the sorting of the entire remainder of the sample. The problem becomes even more acute in regions of the world where the taxonomic literature is inadequate. A second problem with these macrobenthic studies is that many of the means by which pollution can be detected have been developed in north temperate regions and are unlikely to have worldwide applicability, particularly those which rely on the identification of particular indicator species which may not have a cosmopolitan distribution.

Gray et al. (1988) showed in their multivariate analyses that there was a considerable degree of redundancy in the data, subsets of species reproducing closely the patterns produced by the full species set. This type of data reduction does not, of course, help with the problems discussed above but, if the techniques of data analysis were relatively robust to aggregation of species into higher taxonomic groupings, this would obviate the problems considerably. It might then only be necessary to sort the fauna initially into these groupings. Heip et al. (1988) have shown this to be the case for the meiobenthos of Langesundfjord and Frierfjord. Similar experiments with the macrofauna data are therefore appropriate but were not undertaken at the workshop, and have been carried out subsequently.

There are also certain possible theoretical advantages to conducting multivariate analyses at the level of major groups (e.g. phyla). A problem highlighted by Gray et al. (1988) is that confounding natural variables (or 'nuisance' variables) also affect community structure and may mask the effects of pollution. The most important of these natural variables appear to be water depth and sediment granulometry, and in surveys designed to detect pollution effects over relatively 
large areas these will rarely be constant. However, these variables usually influence the fauna more by species replacement than by changes in the proportions of major taxa present. For example, there are changes from communities characterised by the brittlestar Amphiura filiformis in shallow water to those characterised by $A$. chiajei in deeper water (Buchanan 1963), and changes from deposit feeding to suspension feeding species of polychaetes and bivalve molluscs from mud to sand (Sanders 1958), which will not be reflected at the major taxon level. There are strong indications, however, that pollution effects are detectable at this major taxon level. Rosenberg (1972) has documented changes in the proportions of echinoderms, crustaceans, molluscs and polychaetes which occurred with the commissioning and closure of a sulphite pulp mill in a Swedish fjord, while the data of Dauvin (1984) show that even the subtle effects of the Amoco Cadiz oil spill on the macrobenthos of the Bay of Morlaix ( $N$. France) were evidenced at the level of major taxa (in that case, only amphipods were affected). It is a plausible hypothesis, therefore, that ordinations of abundance or biomass data of these major taxa will correlate more closely with a contamination gradient than do species ordinations, the latter being more complicated by the effects of natural environmental variables when large heterogeneous geographical areas are considered.

\section{METHODS}

The macrobenthic species abundance and biomass data from the GEEP Workshop (Gray et al. 1988 and Appendix 3, Tables 1 and 2) have been aggregated at 2 levels: families (52 in number) and phyla (8). Table 1 (this paper) gives the number of families and species in each phylum. In view of the fact that the various multivariate and univariate methods of analysis of the species data were in good agreement with each other (Gray et al. 1988), representative examples of each have been selected for use on the aggregated data.

Table 1. Aggregation of macrobenthic species data into families and phyla

\begin{tabular}{lcc|}
\hline Phylum & No. of families & No. of species \\
\hline Coelenterata & 1 & 1 \\
Nemertina & 1 & 1 \\
Priapulida & 1 & 1 \\
Annelida & 27 & 77 \\
Mollusca & 12 & 16 \\
Arthropoda & 3 & 4 \\
Sipunculida & 3 & 3 \\
Echinodermata & 4 & 6 \\
\hline
\end{tabular}

Classification. Group average sorting of the BrayCurtis similarity measures based on 4 th root transformed and untransformed abundance and biomass data.

Ordination. Multidimensional Scaling (MDS) on the above 4 similarity matrices.

Univariate assessment of disturbance. Comparison of the distribution of numbers of individuals among taxa with the distribution of biomass among taxa (ABC method of Warwick 1986, Warwick et al. 1987). This has not been carried out on data aggregated to phylum level.

\section{RESULTS}

\section{Multivariate analyses}

As with the analyses of species data, the results of classification and ordination for the abundance and biomass data for families and phyla were in very close agreement with each other, and therefore only the ordination configurations are presented here.

$\checkmark \checkmark$ TRANSFORMATION
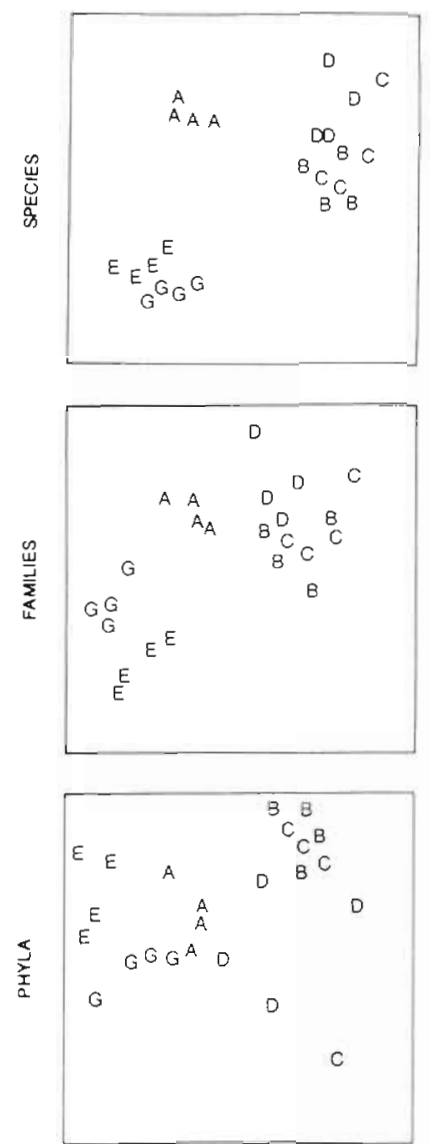

Fig. 1. Multidimensional Scaling (MDS) ordinations in 2 dimensions for abundances of macrotauna species, families and phyla, using 4 th root transformed and untransformed data from 4 grab samples at each of the Field sites $A$ to $E$ and $G$ 
For abundance (Fig. 1), the 4 th root transformed and untransformed data for families were virtually identical to the comparable species analyses, except perhaps that for the 4 th root transformation the replicate samples from Sites $E$ and $G$ were rather better separated at the family level; also A replicates, although clearly still distinct, were slightly closer to the $\mathrm{B}+\mathrm{C}+\mathrm{D}$ cluster. At the phylum level, for the 4 th root transformation, the pattern degenerated severely; only the replicates at Site E clustered together in the classification and were clearly distinct on the ordination. With no transformation of the data, again only E replicates clustered together in the classification, but in the ordination $\mathrm{G}$ and A replicates were also rather more distinct and the general pattern of the family and species configurations was maintained. Clustering of replicates for given sites was not so tight, but rather there was a gradual transition following a U-shaped curve through E-G-A-D-C-B which reflected a similar pattern to the species and family configurations.

For biomass (Fig. 2), ordinations at the family level again produced $2-D$ configurations virtually identical to the species analyses with comparable strengths of data

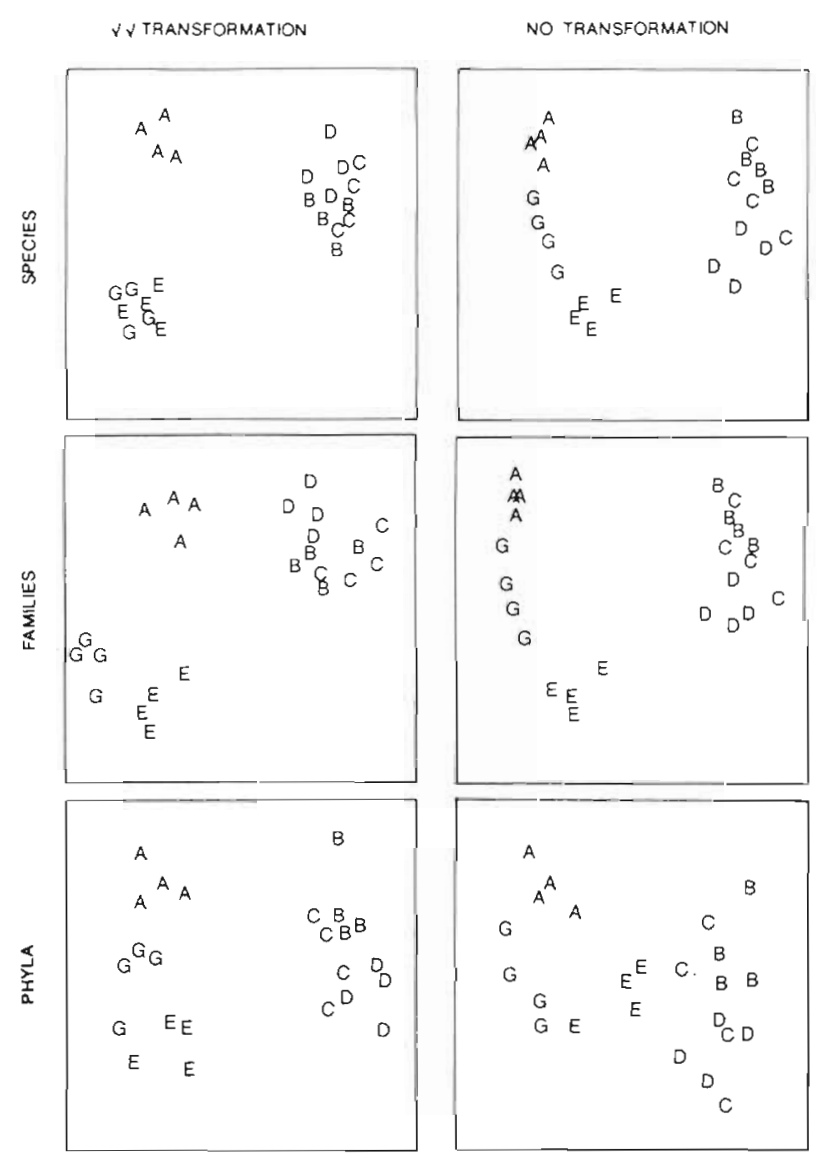

Fig. 2. MDS ordinations for biomass of macrofauna species, families and phyla, using 4 th root transformed and untransformed data transformation. However, for the 4 th root transformed data, the improvement in the separation of $E$ and $G$ replicates was even more appreciable than for the abundance analysis, and there was a rather clearer separation of $D$ replicates within the $B+C+D$ cluster. At the phylum level, for the 4th root transformed data, classification clustered the replicates of Sites A, E and D discretely, B, C and D replicates forming a united cluster. This was also apparent on the 2-D MDS configuration. This configuration is very similar to the comparable species and family analyses, with virtually no loss of information; indeed even at this taxonomic level the separation of $E$ and $G$ replicates is somewhat better than at the species level. For the untransformed biomass data, clustering is again not so discrete as at the species or family level, but there is a similar U-shaped configuration grading through A-G-E-D-C-B.

\section{Univariate analyses}

ABC plots at the family level (Fig. 3) are virtually identical to similar plots at the species level (Fig. 13 of
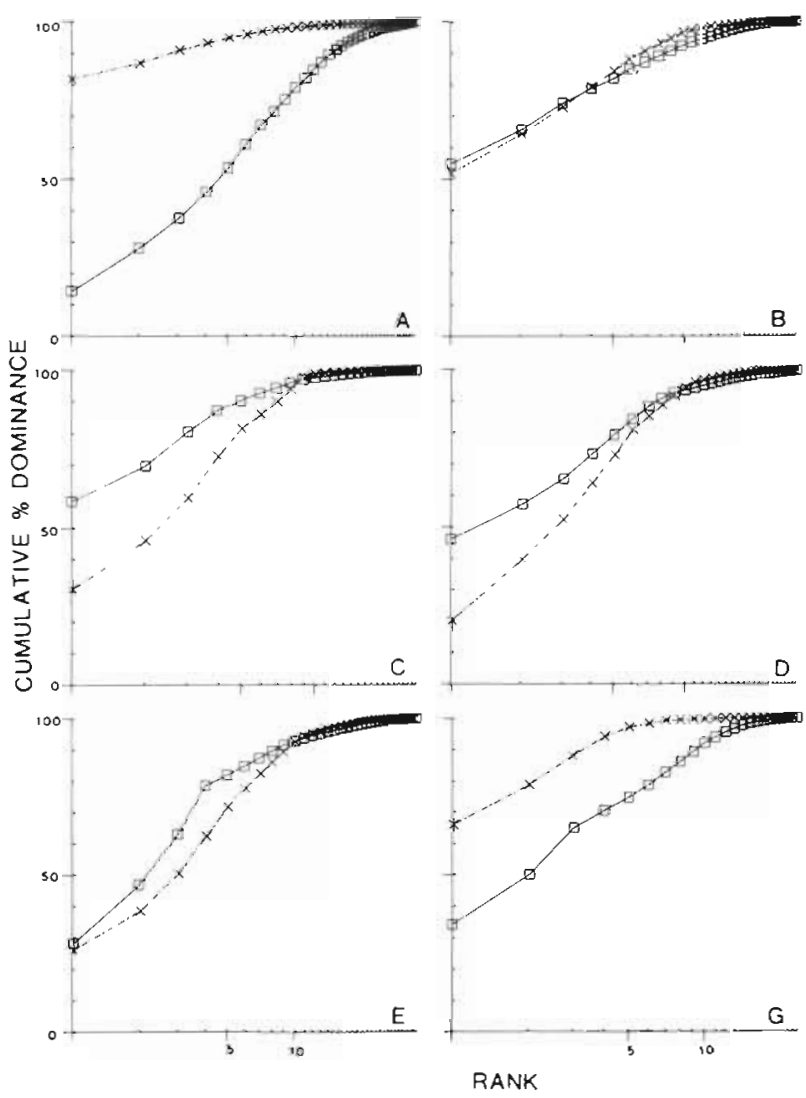

Fig. 3. ABC plots for field macrofauna data aggregated at the family level (cf. Fig. 13 of Gray et al. 1988, for comparable species plots). The $k$-dominance curves for abundance (squares and solid lines) and biomass (crosses and broken lines) are based on totals from the 4 replicates at each site 
Gray et al. 1988). According to Warwick's (1986) criteria they indicate that Sites A and G are 'unpolluted', Sites B and $\mathrm{E}$ 'moderately polluted' and Sites $\mathrm{C}$ and $\mathrm{D}$ 'moderately' to 'grossly polluted'.

\section{DISCUSSION}

The results of the multivariate and univariate analyses applied in this paper, which are considered to be representative of the much wider variety employed by Gray et al. (1988), indicate that no information whatsoever would have been lost if the organisms had been identified to family level only. Indeed, where small differences did occur between the multivariate species and family analyses, these generally reflected slightly better separation of replicates for families. The reasons for this are not immediately obvious. These findings augur well for the application of these techniques both to regions of the world where the fauna is poorly documented and by laboratories lacking specialised taxonomic expertise. Furthermore, even where the taxonomic expertise is available a very appreciable time saving could be made by identifying organisms to family level only, which would greatly increase the costeffectiveness of this type of study.

Multivariate analyses at the phylum level generally produced less tight clustering of replicates within sites than the corresponding species or family analyses, and the overall configurations varied according to whether abundance or biomass data were used, and according to the strength of the data transformation applied. To investigate the suggestion, made in the introduction to this paper, that analyses of higher groups might more clearly reflect gradients of stress and be less affected by natural nuisance variables than species analyses, selection of the appropriate type of data must be made. It should be pointed out that 5 of the 8 phyla in this study were relatively unimportant in terms of either abundance or biomass (Coelenterata, Nemertina, Priapulida, Arthropoda, Sipunculida), so that the analyses were strongly dominated by just 3 phyla (Annelida, Mollusca, Echinodermata). Of these 3, Gray et al. (1988) assert that echinoderms are indicative of unpolluted conditions. In soft bottoms these are rarely the numerical dominants, but may frequently be the biomass dominants, as at Sites A and G. On the other hand, annelids dominate both numerically and in terms of biomass under more stressed conditions, as at Sites $B, C$ and $D$. Thus, the use of biomass data and a weak (or no) transformation, to accentuate the differences between sites, seems biologically the most appropriate if the pollution gradient is to be reflected. MDS of the untransformed biomass data for phyla encouragingly produced the sequence of Sites A-G-E-D-C-B through the 2-D configuration, which is exactly the sequence of increasing levels of stress indicated by the wide variety of univariate indices employed by Gray et al. (1988). This configuration was also evident at the species and family levels. This pattern was not found in any analyses of the abundance data, or for the biomass data with strong transformation. The 4 th root transformed biomass data produced MDS configurations at the phylum, family and species level which were very close to their counterparts for abundance, correlating most closely with the water depth gradient (Gray et al. 1988).

The outcome of any multivariate analysis of this type of data will result from patterns induced by natural environmental variables and modified by the effects of pollution. It might be possible to minimize the part that natural variables play in determining the patterns, and highlight the influence of pollutants or other stressors, by the selection of the most appropriate data format with respect to the measure of importance used for each taxon (abundance or biomass), the strength of the transformation applied to this measure and the level of taxonomic aggregation. It is obviously not possible from this one study to suggest firm protocols but common patterns will hopefully emerge from similar empirical analyses of other data sets.

Acknowledgements. I am grateful to Bob Clarke, Martin Carr and Helen Archer, who in various ways gave advice and/or computing assistance.

\section{LITERATURE CITED}

Buchanan, J. B. (1963). The bottom fauna communities and their sediment relationships off the coast of Northumberland. Olkos 14: 154-175

Dauvin, J.-C. (1984). Dynamique d'ecosystemes macrobenthiques des fondes sedimentaires de la Baie de Morlaix et leur perturbation par les hydrocarbures de l'Amoco Cadiz. Doctoral thesis, Univ. Pierre et Marie Curie, Paris

Gray, J. S., Aschan., M., Carr, M. R., Clarke, K. R., Green, R. H., Pearson, T. H., Rosenberg R., Warwick, R. M. (1988). Analysis of community attributes of the benthic macrofauna of Frierfjord/Langesundfjord and in a mesocosm experiment. Mar Ecol. Prog. Ser. 46: 151-165

Heip, C., Warwick, R. M., Carr, M. R., Herman, P. M. J., Huys, R., Smol N., Van Holsbeke, K (1988). Analysis of community attributes of the benthic meiofauna of Frierfjord/ Langesundfjord. Mar. Ecol. Prog. Ser. 46: 171-180

Rosenberg, R. (1972). Benthic faunal recovery in a Swedish fjord following the closure of a sulphite pulp mill. Oikos 23 $92-108$

Sanders, H. L. (1958). Benthic studies in Buzzards Bay. I. Animalsediment relationships. Limnol Oceanogr 3: 245-258

Warwick, R. M. (1986). A new method for detecting pollution effects on marine macrobenthic communities. Mar. Biol. 92: $557-562$

Warwick, R. M., Pearson, T H., Ruswahyuni (1987). Detecting pollution effects on marne macrobenthos: further evaluation of the species abundance/biomass method Mar Biol. 95: $193-200$ 